Social Protection \& Jobs Global Practice February 2019

Europe and Central Asia Region

\title{
Uzbekistan \\ Social Assistance Targeting Assessment
}




\section{Table of contents}

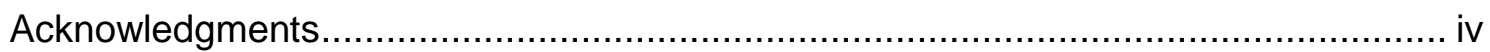

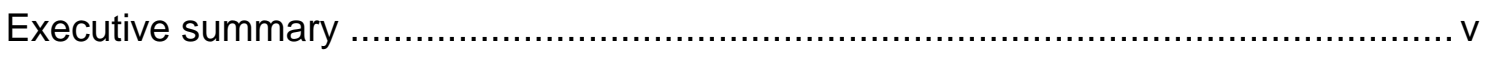

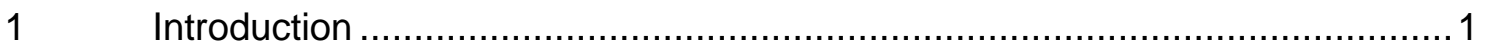

1.1 Conceptual framework and methodology ......................................... 1

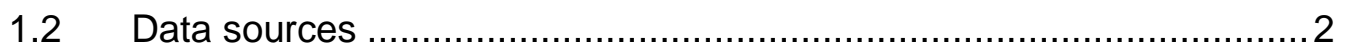

$2 \quad$ Overview of social protection programs

2.1 Beneficiaries and administration of social assistance programs ........... 7

3 An assessment of the targeting performance of social insurance and social

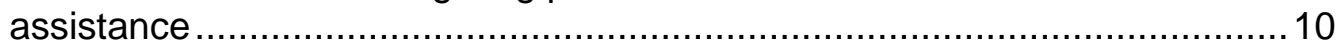

3.1 Coverage and inclusion and exclusion errors............................... 10

3.2 Amount of transfer and poverty impact ........................................... 12

$4 \quad$ Implementation of targeting procedures …........................................... 15

4.1 Administrative processes for low-income family allowances.............. 15

4.2 Administrative processes for other allowances managed by the Pension Fund ............................................................................ 21

4.3 Public works and employment services.......................................22

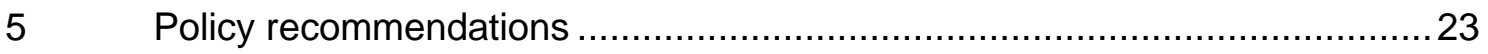

$5.1 \quad$ Low-income family allowances..................................................... 23

5.2 Other social assistance programs .......................................... 25

5.3 Public works and employment services.....................................25

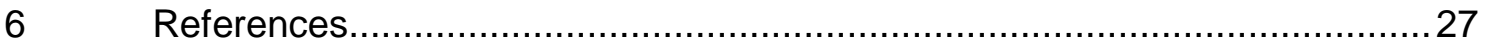

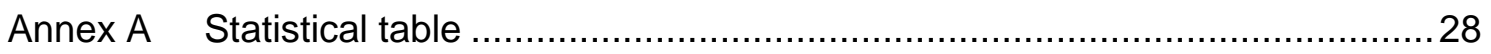

\section{List of tables and figures}

Table 1: $\quad$ Main social protection programs in Uzbekistan ................................ 6

Figure 1: Disentangling design and implementation problems .........................

Figure 2: $\quad$ Geographical coverage of qualitative study..................................... 3

Figure 3: $\quad$ Number of beneficiaries of main social assistance transfers, $2015 \ldots . .7$

Figure 4: $\quad$ Monthly amount of different types of low-income family allowances, December 2017-October 2018...

Figure 5: Number of families that are beneficiaries of low-income allowances, 2013-2017 9 
Figure 6: $\quad$ Coverage of social insurance and social assistance ….....................11

Figure 7: $\quad$ Coverage of different social protection programs ............................. 11

Figure 8: $\quad$ Distribution of beneficiaries of different social protection programs by quintile and poverty status

Figure 9: $\quad$ Transfer as a percentage of consumption expenditure of beneficiaries 13

Figure 10: Effect of low-income family allowances on poverty and relevant errors 14

\section{List of Abbreviations}

$\begin{array}{ll}\text { ESC } & \text { Employment Support Center } \\ \text { FGD } & \text { Focus group discussion } \\ \text { Khokimiyat } & \text { Local authority administration } \\ \text { KII } & \text { Key informant interview } \\ \text { L2CU } & \text { Listening to the Citizens of Uzbekistan } \\ \text { Mahalla } & \text { Local self-government community } \\ \text { MELR } & \text { Ministry of Employment and Labour Relations } \\ \text { MoF } & \text { Ministry of Finance } \\ \text { NGO } & \text { Nongovernmental organization } \\ \text { PF } & \text { Pension Fund } \\ \text { PPP } & \text { Purchasing power parity } \\ \text { PWD } & \text { Persons with disabilities } \\ \text { VTEK } & \text { Labor and Medical Expert Commission } \\ \text { US\$ } & \text { United States dollar } \\ \text { UZS } & \text { Uzbek som }\end{array}$




\section{Acknowledgments}

This report was prepared by a team comprising Ludovico Carraro (Consultant, the World Bank), Maddalena Honorati (Senior Economist, the World Bank) and Manuel Salazar (Lead Social Protection Specialist, the World Bank) under the guidance of Cem Mete (Practice Manager) and Hideki Mori (Country Manager). Trinidad Berenice Saavedra Facusse (Consultant, the World Bank) provided excellent data analysis support. Kakhramon Yusupov (Consultant, the World Bank) coordinated the qualitative data collection undertaken by Al Mar Consulting and provided inputs throughout the process Ruslan Yemtsov (Lead Economist, the World Bank) and Phillippe Leite (Senior Social Protection Specialist) served as peer reviewers and offered valuable insights to the paper. William Hutchins Seitz provided excellent comments.

The study was made possible thanks to the Rapid Social Response multi-donor Trust Fund grant "Supporting Uzbekistan's Inclusive Economic reform through Strengthening its Social Protection System". 


\section{Executive summary}

This report presents the results of a diagnostic study on the targeting of social protection programs in Uzbekistan with a specific focus on low-income family allowances. The objective is to determine the extent to which current programs are reaching the poor and are able to reduce poverty, and consequently to identify ways to improve the current design features and implementation processes. The study is part of the collaboration between the Government of Uzbekistan and the World Bank in improving the effectiveness of social protection.

Targeting is the overall process that enables the administration to inform potential beneficiaries through outreach activities, facilitate application procedures, and assess needs and eligibility to finally enroll beneficiaries. Therefore, targeting involves the delicate process of identifying and selecting beneficiaries.

To assess how targeting works and if it is successful, the study used two main data sources: the Listening to the Citizens of Uzbekistan (L2CU) household survey and a qualitative study that conducted interviews and focus group discussions (FGDs) in four different regions of the country. Both data sources are very recent as they were collected between May and September 2018. The household survey was used to determine the extent to which poor people receive support and to assess the scale of exclusion and inclusion errors. The qualitative study focused on implementation of targeting procedures, looking at regional differences and identifying eventual problems in putting into practice national guidelines.

Uzbekistan has a relatively articulated and comprehensive social protection system that includes social insurance schemes (contributory), social assistance (noncontributory), and labor market programs.

By far the programs with the largest population coverage are social insurance programs and in particular old-age contributory pensions, but it is social assistance that ensures a higher coverage of the poor. Moreover, within social assistance the most important program is low-income family allowances. This program is further divided into three programs: a child care allowance for families with at least one child under two years of age; a children allowance for families with at least one child aged two to thirteen; and financial assistance for other households that face specific difficulties as a result of disability, old age, or other specific problems. All three programs share the same eligibility criteria (per capita income has to fall below a set income threshold) and the same procedures to verify their low-income status. However, once households are enrolled into the program, the amount of support varies as well as the duration of the validity of their eligibility.

The number of households receiving low-income family allowances declined continuously in recent years, and in 2017 was almost one-half the number of beneficiaries in 2013. In 2018 the Government of Uzbekistan increased budget availability for this program, however, and the number of beneficiaries is expected to increase as well.

Analysis of the household survey data determined the extent to which the poor are reached by different programs, the relative targeting accuracy, and the impact of programs on poverty reduction. In this analysis the poor are defined as people with a consumption expenditure lower than the daily international poverty line of US\$3.2 in 
purchasing power parity. The survey estimates that just under 10 percent of people are poor in Uzbekistan.

While overall the distribution of beneficiaries of social assistance programs, particularly of low-income family allowances, across quintiles is good, the analysis identified three main problems:

1) Large exclusion errors: 63 percent of the poor are not reached by low-income allowances;

2) Inclusion errors: 62 percent of beneficiaries of low-income allowances are nonpoor;

3) Suboptimal transfer amounts: while for child care allowances the transfer amount is very high, support is very low for children allowances, even though the income and living conditions of households eligible for either one are likely to be the same. This imbalance means that among the poor receiving support, only onehalf are pushed above the poverty line.

The above results can be the effect of both design problems and implementation difficulties. While this study did not fully disentangle the two problems, the qualitative study tried to identify possible implementation errors.

Key findings are that 1) no common standards exist for outreach activities, and 2) there is a need to better define who belongs to the same household and for procedures to impute income, as well as to standardize the way living conditions are assessed and verified. Moreover, one of the main reasons for exclusion errors is the use of caps in budgeting and in the number of beneficiaries at the local level.

The study also looked at the outreach activities, eligibility assessment, and enrolment procedures of other social assistance allowances administered by the Pension Fund and employment programs and public works promoted by the Employment Support Centers.

The analysis produced a number of practical recommendations to improve the current targeting of programs in Uzbekistan:

- Produce clear guidelines on outreach approaches that should be followed to improve knowledge and access to social assistance allowances;

- Understand and address reasons for capped numbers of beneficiaries and capped budgets at local level, so that budget allocations are not simply based on previous expenditure, but reflect a needs assessment of the population; the social registry would be of great advantage for such an approach;

- Provide a more detailed definition of a "household" and guidelines on how to implement the definition;

- Conduct further analysis of the L2CU survey or the Household Budget Survey to simulate income eligibility and develop more robust rules for the income assessment (imputation rules) as well as the appropriate eligibility threshold;

- Develop a proxy means test as a system to limit inclusion errors and simulate its ability to improve the current targeting mechanism;

- Ensure the traceability of application and accountability of personnel engaged in the administration of low-income family allowances; 
- Using the L2CU survey or the Household Budget Survey, better assess how to optimize the correct amount of transfers;

- Review the reapplication procedures to ensure that no interruption exists if households continue to meet the eligibility criteria;

- Review the current mechanisms of assessing disability and relative requirements for the confirmation of disability status over time;

- Improve the integration of social assistance for low-income households and employment services. 


\section{Introduction}

As part of the collaboration between the Government of Uzbekistan and the World Bank in improving the effectiveness of social protection, the Bank conducted a diagnostic study on the targeting of social assistance programs. The main objective of the study is to determine the extent to which social assistance is reaching poor and vulnerable populations and whether some implementation aspects in the targeting process could be improved. Indeed, the study examines the implementation procedures that help in identifying, selecting, and enrolling beneficiaries of social assistance with the aim of assessing whether elements of the process could be strengthened. This could inform areas of potential further work and collaboration between the Government of Uzbekistan and the World Bank.

\subsection{Conceptual framework and methodology}

The study intends to answer a number of key questions: Are poor people reached by social assistance programs? Are there significant inclusion or exclusion errors? Are the current programs adequate? How are potential beneficiaries informed and how do they apply for social assistance? How are they selected and enrolled in different programs? Are these systems effective? Are people treated fairly across the country?

To answer such questions the study uses two main sources of data: a nationally representative household survey (Listening to the Citizens of Uzbekistan, or L2CU) and a qualitative study with focus group discussions (FGDs) and in-depth interviews across different regions of Uzbekistan. The household survey was used to determine the extent to which poor people receive support and to assess the scale of exclusion and inclusion errors. The qualitative study focused on implementation of targeting procedures, looking at regional differences and identifying eventual problems in putting into practice national guidelines. Therefore, the qualitative study aims at answering "why" questions that could explain the source of exclusion or inclusion errors.

Targeting is the overall process that enables the administration to inform potential beneficiaries through outreach activities, facilitate application procedures, and assess needs and eligibility to finally enroll beneficiaries. Whenever social assistance is granted for a short period of time, the study also includes the process used to reconfirm eligibility and manage reapplications. Therefore, targeting involves the delicate process of identifying and selecting beneficiaries.

The literature recognizes that targeting always involves two types of errors:

- Exclusion error: not all intended beneficiaries actually receive the program;

- Inclusion error: some people who were not intended beneficiaries receive the program.

In the case of social assistance there are good reasons to argue that the intended population should be the poor. Therefore, when poor people do not receive social assistance, an exclusion error arises; conversely, when nonpoor people receive social assistance, an inclusion error occurs.

However, it is important to be aware that exclusion and inclusion errors can be the effect of two different problems: design and implementation. Design failures and inconsistencies can lead to high errors of exclusion or inclusion. For instance, sometimes programs have eligibility rules that unintentionally promote the exclusion of individuals who are supposed to be targeted or that leave room for leakages (errors of inclusion). On the other hand, even perfectly well-designed programs can be ineffective since many issues can arise when 
implementing the targeting strategy in the field, jeopardizing its effectiveness. For example, if a certain social program does not conduct proper communication campaigns, many "eligible" households may never be aware of the existence of the benefit or of their eligibility, and therefore do not apply. In that case, the program will be highly inefficient since it will face important errors of exclusion regardless of its design.

Figure 1 captures these distinctions, showing 1) how design errors arise from the mismatch between the target group (the poor in the figure) and the eligible population (the way in which the targeting mechanism identifies the eligible), and 2) how implementation errors arise from the mismatch between eligible and actual recipients of the program. This disentangles the combined errors whereby the extent to which the recipients are poor is examined.

\section{Figure 1: Disentangling design and implementation problems}

Design issues

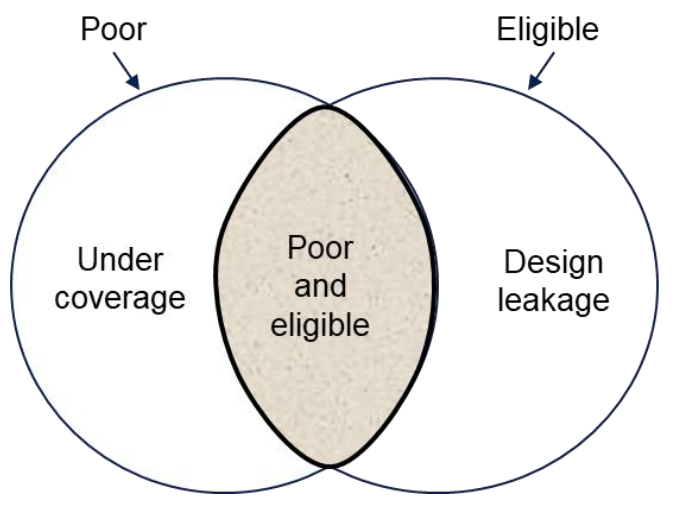

Implementation issues

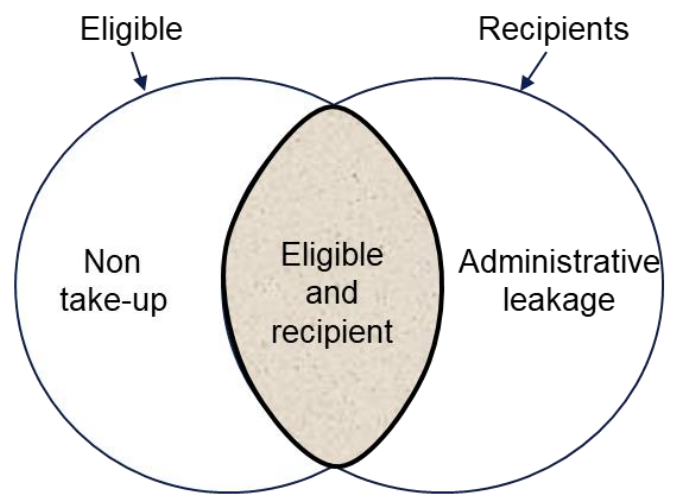

A final element in the targeting assessment concerns not only the overlap between the poor and recipients, but also the level of support; i.e., whether the cash or in-kind transfer and the services provided are sufficient to improve recipients' living conditions.

\subsection{Data sources}

Two main data sources were used for this assessment: a nationwide country representative household survey and a qualitative assessment.

The quantitative L2CU survey interviewed just over 4,000 households between May and August 2018, covering around 200 mahallas across the country in both urban and rural areas and across the 14 regions of Uzbekistan (12 provinces, Karakalpakstan and Tashkent City). The survey also focused on beneficiaries of social benefits and purposively oversampled them to be able to provide reliable estimates for this specific subgroup of the population.

The questionnaire collected information on a broad number of topics: household composition, migration, education, health, employment, banking and savings, social benefits, household income, consumption expenditure, dwelling characteristics, and people's opinions of the current quality of infrastructure facilities, the performance of local administrative organizations, and the priority of different types of interventions.

Information collected in the survey enables calculation of both household income and household consumption expenditure, which can be used as welfare indicators once adjusted by household size and composition as well as differences in prices. In this analysis 
the preferred welfare measure is per capita consumption expenditure, which was used to group the population in quintiles, each containing 20 percent of the population, and ordered from poorest to richest. It was also used to identify the poor, defined as the group of people who fall below the daily international poverty line of US $\$ 3.2$ in purchasing power parity (PPP).

The qualitative study was also conducted between May and September 2018, and involved a mixture of FGDs and key informant interviews (KIls). The study did not aim to be country representative, but was conducted in various parts of the country to ensure coverage of different contexts and situations. More specifically, the study was conducted in four different regions: Tashkent city, Fergana, Khashkadarya, and Karakalpakstan (Figure 2 shows the specific locations included in the study). In all regions but Tashkent city, interviews occurred within four different mahallas: one in urban areas and three in rural areas (for more information on the qualitative study, see Al Mar Consulting 2018).

In each mahalla two FGDs were conducted, one with beneficiaries of social transfers and another with nonbeneficiaries that were relatively poor households (either ex-beneficiaries, or people who applied for some form of support but were rejected). Discussions covered knowledge of social assistance programs, the application process, and the importance of the support received.

KIls were conducted with the district Khokimiyat, Employment Support Center (ESC), and Pension Fund (PF) as well as with mahalla representatives. Interviews covered existing government interventions with a specific focus on social protection programs and possible areas of improvement with the aim of understanding procedures and their implementation. Interviews were also held at the central level with the Ministry of Employment and Labour Relations (MELR), the Ministry of Finance (MoF), and the Republican PF to understand the whole administrative process.

Figure 2: Geographical coverage of qualitative study

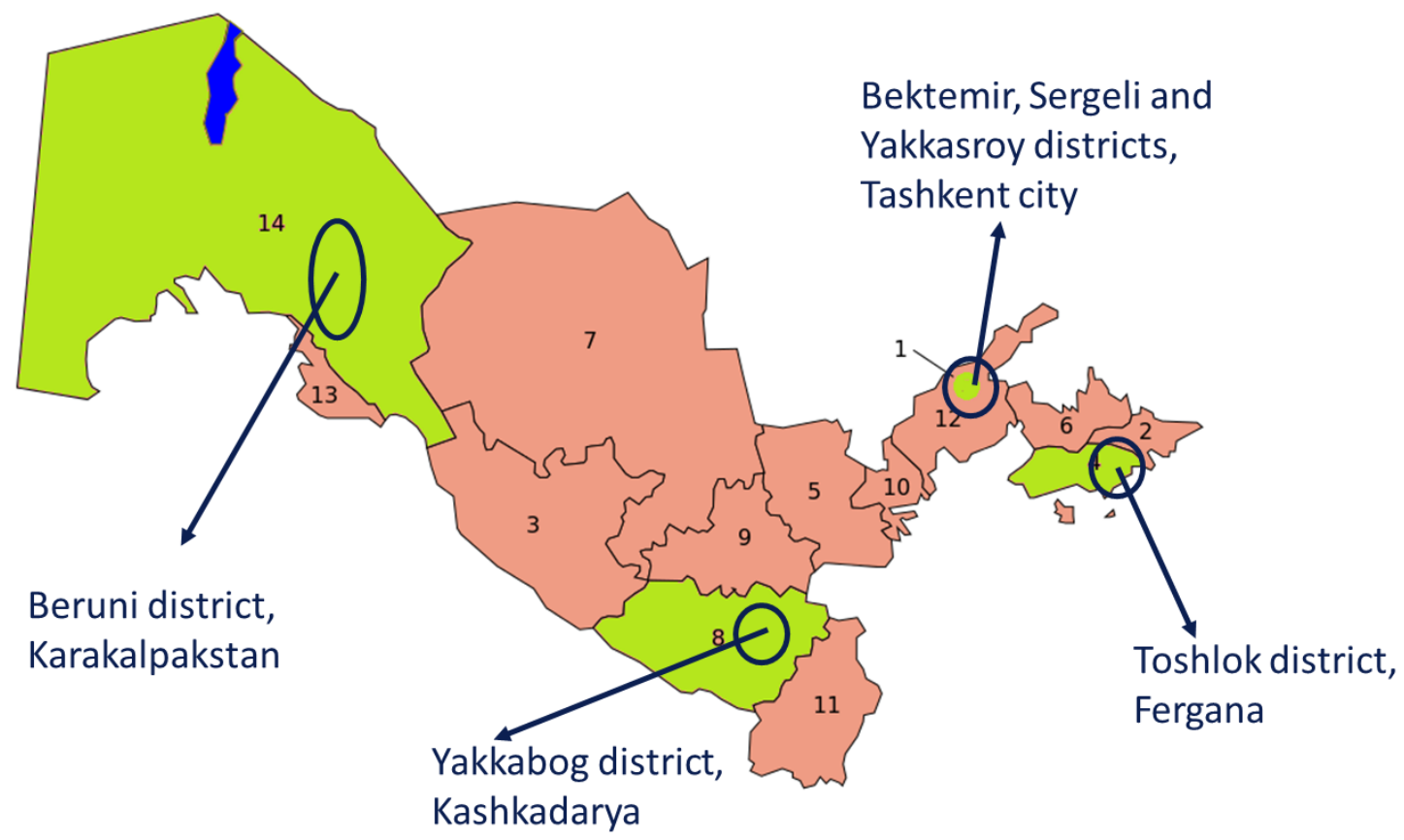

The remainder of the report is organized as follows. The next section presents the main social protection programs in Uzbekistan with a specific focus on social assistance and low- 
income family allowances. The third section summarizes the evidence from the analysis of the L2CU survey on the general performance of the social protection programs in terms of coverage, exclusion and inclusion errors, transfer amounts, and the simulated impact of social assistance on poverty reduction. The fourth section summarizes the results of the qualitative study, identifying the main implementation problems and how these can affect targeting. The last section draws key implications for possible improvements in the targeting system. 


\section{Overview of social protection programs}

Uzbekistan has a relatively articulated and comprehensive social protection system that includes social insurance schemes (contributory), social assistance (noncontributory), and labor market programs.

The various existing programs are summarized in Table 1. Entitlement to social insurance programs is conditional on contributions that people make when they work and are supposed to protect people during old age or maternity, or in case of accidents and sickness.

Social assistance benefits include four types of programs:

- cash allowances provided to low-income households (means-tested benefits);

- cash allowances provided to the elderly, persons with disabilities (PWD), and survivors (breadwinner loss);

- allowances in case of special events or shocks;

- allowances, discounts, and in-kind support to vulnerable groups.

The first type of allowances is means tested, i.e., conditional on household income being below a fixed eligibility threshold (expressed in per capita terms and equal to 1.5 times the minimum wage, ${ }^{1}$ which from December 2017 until October 2018 was UZS 172,240 per month).

The second type of support mirrors social insurance programs but intervenes whenever people did not make any contributions or did not reach the minimal level of contributions. This is the case for old-age, disability, and survivors' allowances. By design, support provided through these schemes comes with lower amounts and stricter criteria than pensions whose entitlement is based on contributions. For example, old-age allowance is provided only if people do not have other income sources (are not in employment and do not have other family members ${ }^{2}$ who can take care of them). While the minimum old-age pension is UZS 336,000 per month, the old-age social allowance is UZS 207,000 per month. ${ }^{3}$ Moreover, while the old-age pension is provided at the age of 60 and 55 for men and women, respectively, the old-age allowance is granted at the age of 65 and 60 .

Allowances provided in case of special events or shocks consist of birth and funeral allowances, and in the Republic of Karakalpakstan and Khorem region, a one-off financial assistance. This one-off financial assistance is provided if a household is in a difficult situation because of severe disease, death of household members, natural disasters, accidents, fires, or other emergency situations. Such allowance can be provided once per year and its value can be between two and five times the minimum wage depending on the severity of the household's circumstances.

Finally, allowances, in-kind support, and discounts are provided to vulnerable groups. These include support to afford expenditures on utilities, use of public transport and medicines, winter clothes, and food. Usually such support is provided to the elderly and PWD, but support for winter clothes is provided to children of families with low income who

\footnotetext{
1 The minimum wage is not an actual minimum wage for employees, but a basic reference amount used to set most transfers in the country.

2 These are defined based on the Family Code of the Republic of Uzbekistan.

3 These values were in place between December 2017 and September 2018.
} 
are attending school. Most of these allowances are complementary to the cash allowances provided under the above programs.

A final item included within the noncontributory support consists of social care services, which are provided to children, the elderly, and PWD, partly through residential institutions and community services.

Concerning labor market programs, various interventions and schemes exist, all provided by the MELR through the district-level ESC. Unemployment benefits are granted for a short period of time to people registered as unemployed in the ESC. Public works schemes were first piloted in the last quarter of 2017 and started to be promoted nationwide since the beginning of 2018. They consist of both subsidized employment in the private sector and public employment offered by government agencies for a period between 15 days and 3 months per year. Microloans are also provided at preferential interest rates to promote selfemployment and entrepreneurship. There are also services aimed at supporting entry in the labor market through training, apprenticeships, and job intermediation.

\section{Table 1: Main social protection programs in Uzbekistan}

\begin{tabular}{|c|c|c|}
\hline $\begin{array}{l}\text { Social Insurance } \\
\text { (contributory) } \\
\text { Deliver: district level } \\
\text { Pension Fund (MOF) }\end{array}$ & $\begin{array}{l}\text { Social Assistance (noncontributory) } \\
\text { Delivery: through mahallas }\end{array}$ & $\begin{array}{l}\text { Labor market programs } \\
\text { Delivery: district-level } \\
\text { ESC (MELR) }\end{array}$ \\
\hline $\begin{array}{l}\text { Old-age pension } \\
\text { Disability pension } \\
\text { Breadwinner loss } \\
\text { Childbirth leave and } \\
\text { benefit } \\
\text { Sickness leave and } \\
\text { benefit } \\
\text { Other social insurance }\end{array}$ & $\begin{array}{l}\text { Low-income family allowances (child } \\
\text { allowance for children <2; children } \\
\text { allowances for children aged 2-13; and } \\
\text { financial assistance) } \\
\text { Old-age allowance } \\
\text { Disability allowance (since childhood or } \\
\text { acquired) } \\
\text { Breadwinner loss allowance } \\
\text { Birth and funeral allowance } \\
\text { One-off financial assistance in the } \\
\text { Republic of Karakalpakstan and Khorem } \\
\text { region } \\
\text { Monetary compensation for communal } \\
\text { expenses to vulnerable groups } \\
\text { In-kind support: free-of-charge winter } \\
\text { clothes to school children, use of public } \\
\text { transport, food provision, medicines } \\
\text { Social care services }\end{array}$ & $\begin{array}{l}\text { Unemployment benefits } \\
\text { Public works } \\
\text { Microloans } \\
\text { Professional training } \\
\text { Apprenticeships } \\
\text { Job intermediation and } \\
\text { matching service } \\
\text { Employment subsidies } \\
\text { (2019) }\end{array}$ \\
\hline
\end{tabular}

Social insurance programs, and in particular old-age pensions, comprise by far the largest share of the budget, with a very high coverage of the population. Based on figures provided by the PF as of October 1, 2018, 2.58 million people receive old-age pensions, 366,000 receive disability pensions, and 169,000 receive survivors' pensions. Numbers of recipients of noncontributory social assistance are significantly smaller, but are nevertheless very important for poor and vulnerable people. Finally, labor market programs are of relatively lower importance in terms of budget given their short-term nature of support. 


\subsection{Beneficiaries and administration of social assistance programs}

It is important to be aware that social assistance is provided through two distinctive administrative channels: the mahallas and the Khokimiyat are responsible for the administration of the low-income family allowances as well as the one-off assistance provided in the Republic of Karakalpakstan and Khorem region, whereas almost all other social allowances are administered through the PF, which has district-level offices. The ESC is responsible not only for labor market programs, but also has a monitoring function for the low-income family allowances. Significant exceptions are the distribution of winter clothes to school children of low-income families administered through the Ministry of Public Education and special services to the elderly and PWD administered through the Ministry of Health.

However, the focus here is primarily on low-income family allowances and assistance provided through the PF. Thus it is relevant to identify the number of beneficiaries and recent trends in their numbers, and the level of support provided through these allowances.

Based on figures provided by the PF as of October 1, 2018, 312,000 people receive social allowances. This includes allowances provided only by the PF, but no breakdown of the different types of allowances is available. Instead, a more detailed picture of the relative importance of the different social assistance allowances is given in Figure 3 for 2015. Lowincome family allowances are by far the most important benefits in terms of number of beneficiaries. Moreover, while social allowances are counted at the individual level, lowincome family allowances are provided at the household level.

Within social allowances, the largest number of beneficiaries comes from disability allowances provided to PWD since childhood (130,000 out of the 175,000).

Figure 3: Number of beneficiaries of main social assistance transfers, 2015

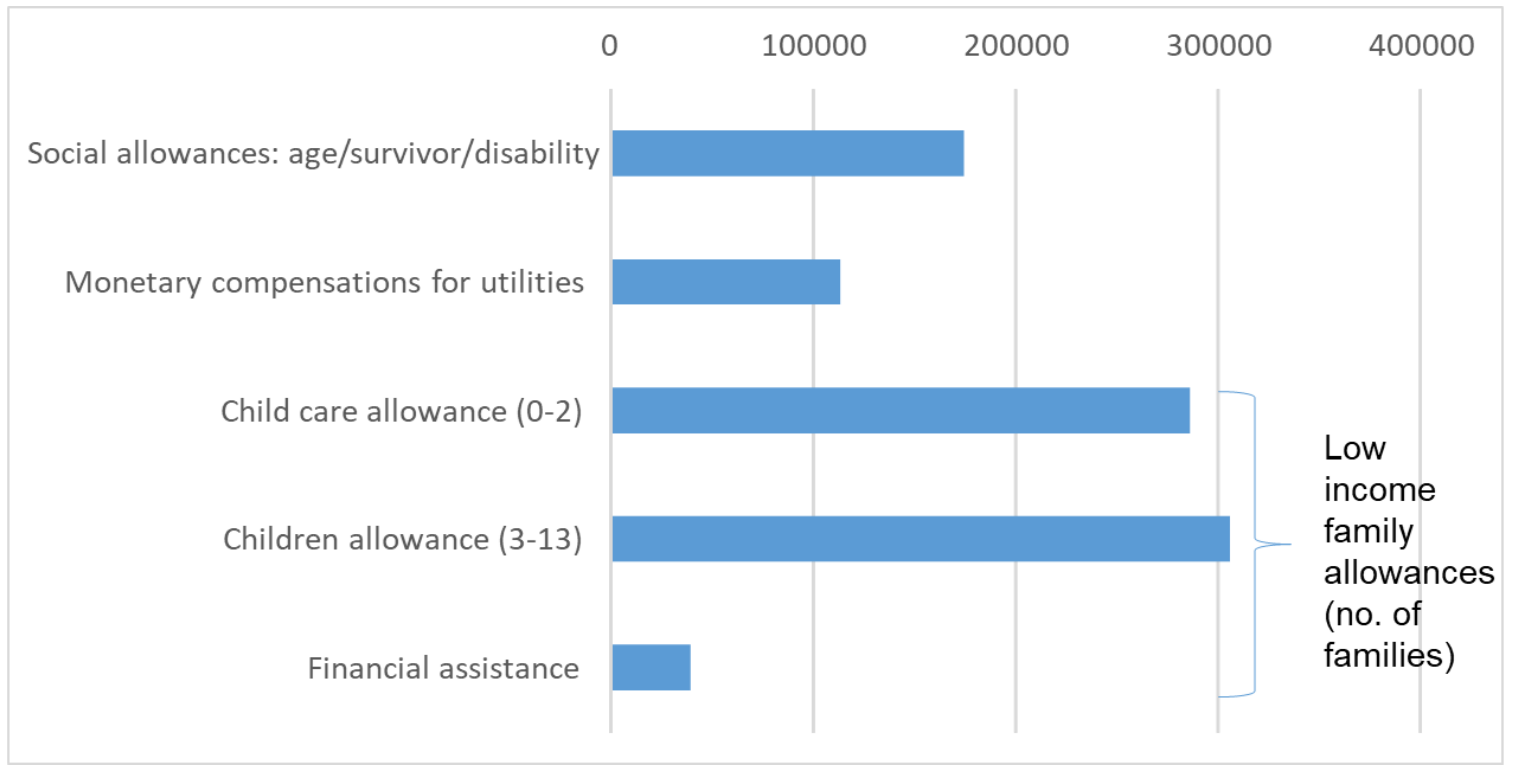

Source: Ministry of Finance.

It is also relevant to determine the amount of support provided through these different allowances. The amount for most social allowances from December 2017 was set at UZS 206,720 per month (old-age and disability allowance), whereas the amount for disability 
since childhood was UZS 336,880 per month. The monthly compensation for utilities was 25 percent, 45 percent, or 50 percent of the minimum wage, depending on the vulnerability category to which people belong. Figure 4 shows the amount of transfers for the three types of low-income family allowances.

It is important to emphasize that for all three low-income family allowances, the fundamental eligibility criteria are exactly the same; i.e., per capita household income must be lower than 1.5 times the minimum wage (between December 2017 and October 2018, UZS 258,360 per month). Moreover, the procedures to calculate income and to conduct the household needs assessment are exactly the same (this is regulated by the Resolution of the Cabinet of Ministers No. 44 of February 15, 2013 [hereafter referred to as CR \#44]). Instead, what determines the amount of support is the composition of the household: whether there is a child less than 2 years old (child care allowance), whether there are children between the age of 2 and 13 and their number (children allowances), or whether the household faces specific bad circumstances or specific challenges, such as disability (financial assistance). In such cases the level of support can vary between the standard amount of 1.5 times the minimum wage to up to 3 times the minimum wage for complex cases. In practice, the highest amount is very rarely awarded. However, it is very relevant to note that the amount of support does not depend on the number of household members, and it is puzzling that the amount can vary so significantly across the three allowances, even though the eligibility criteria are identical.

Figure 4: Monthly amount of different types of low-income family allowances, December 2017-October 2018

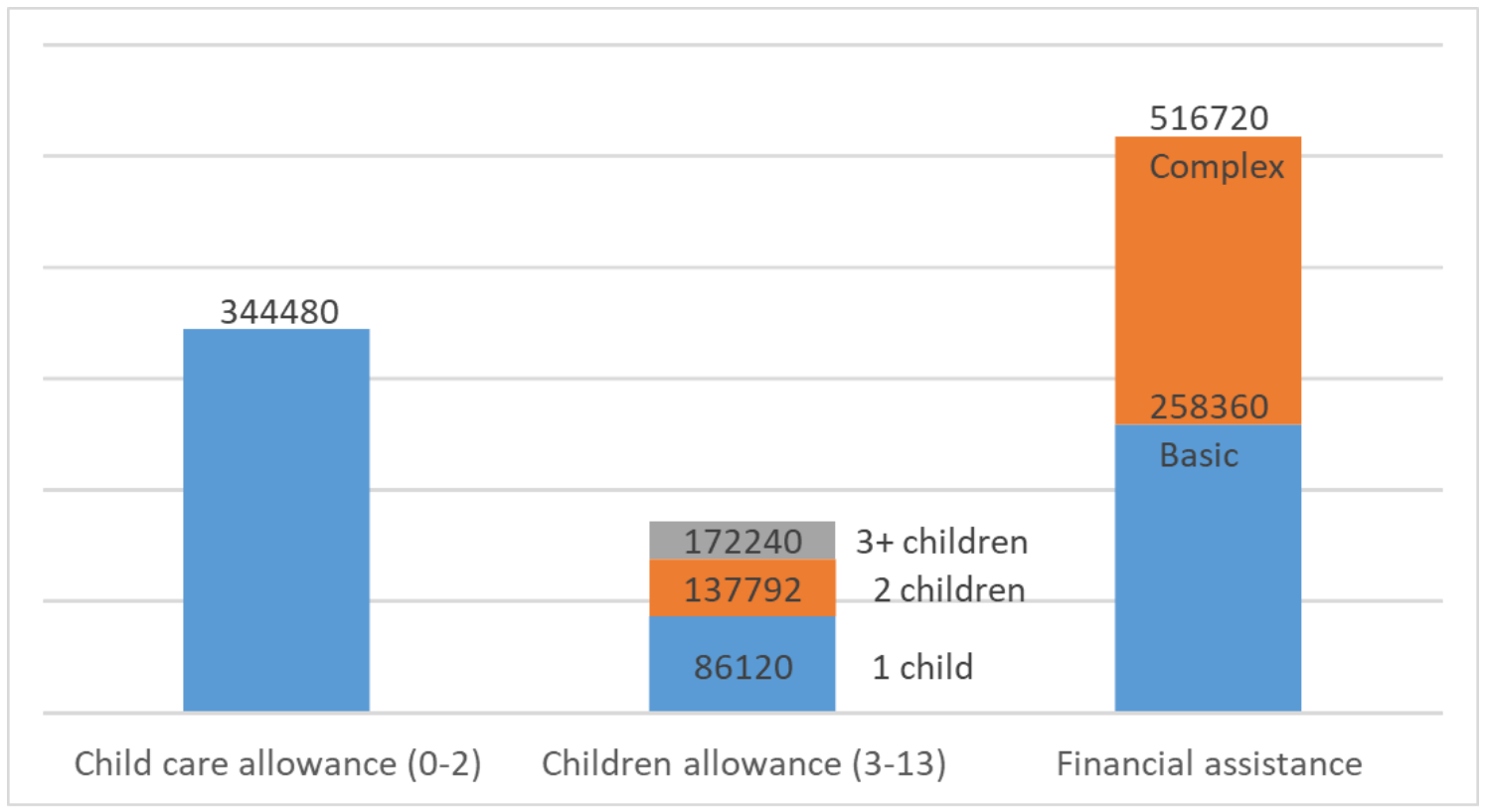

Source: Ministry of Finance.

Finally, it is useful to get a perspective on the trends in the recipients of low-income family allowances. The number of beneficiaries of such allowances has been declining; in 2017 the number was almost one-half of the number of beneficiaries in 2013, especially for allowances for children aged 2-13 (Figure 5). In 2018 it is expected that the number of beneficiaries will increase, as more funding was allocated to these allowances, but official comparable numbers for 2018 are not yet available. Nevertheless, the planned number of beneficiaries is included here. 
Figure 5: Number of families that are beneficiaries of low-income allowances, 20132017

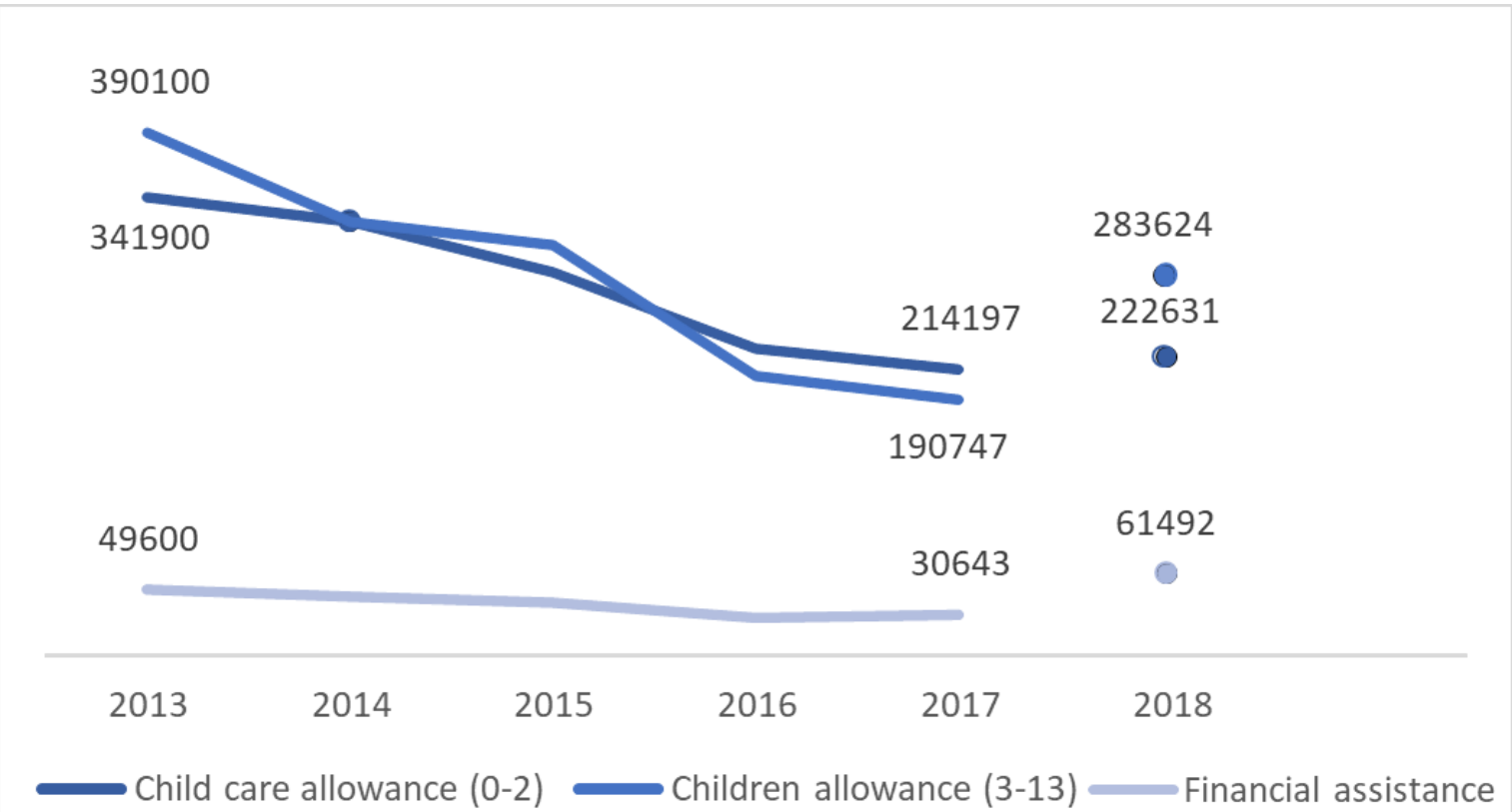

Source: Ministry of Finance. 


\section{An assessment of the targeting performance of social insurance and social assistance}

The performance of Uzbekistan's social protection system can be assessed in terms of coverage of the population and specifically of the poor, the level of transfers in relation to beneficiaries' consumption levels, and the overall impact of the transfers on poverty.

\subsection{Coverage, inclusion and exclusion errors}

As explained in the introduction, the L2CU survey was used to construct an indicator of welfare using the per capita consumption expenditure, to identify households that fall below the international poverty line of US\$3.2 PPP, and to divide the population in quintiles from poorest to richest. This information is used to calculate the percentage of recipients among different quintiles, by both poverty status and urban/rural area. As a starting point it is useful to know that overall the L2CU survey estimated that just under 10 percent of the population in Uzbekistan falls below the international poverty line.

Unfortunately, labor market programs were not adequately captured in the L2CU survey, ${ }^{4}$ so results are presented only for social insurance and social assistance programs before looking in more detail at the findings for low-income family allowances.

Figure 6 shows the percentage of people receiving at least one social insurance transfer or social assistance transfer across the whole population, by poverty status and in urban and rural areas. It is important to clarify that the calculation provides figures for direct and indirect beneficiaries, which means that if one household member receives a transfer, all members are indirectly beneficiaries.

Overall, population coverage is relatively high, and increases further among the poor, with social assistance disproportionally targeted to the poor. People in rural areas are also a bit more likely to receive social assistance than citizens in urban areas (Annex A provides results by quintile).

These figures can be further disaggregated to look at different programs (Figure 7). The L2CU questionnaire asked in some detail about different transfers, but estimates are presented for "old-age pension," "disability pension," "other social insurance" (which groups together survivors' pension, sickness leave, and childbirth leave), "low-income family allowances," "old-age allowance," and "other social assistance" (which groups together disability allowance, survivors' allowance, monetary compensations, and various in-kind support). Figure 7 clearly shows the large role played by old-age pensions, but also how low-income family allowances have a relatively high coverage among the poor. Finally, a word of caution should be given to the "old-age allowance," as this could have partly been misreported since people are often not able to distinguish between "allowance" and "pension." Instead, results for the low-income family allowances are more robust because such households were purposively selected as part of the sampling frame based on administrative data.

\footnotetext{
${ }^{4}$ While the questionnaire asked about involvement in public works and unemployment benefits, very few observations were recorded. There are reasons to believe that the question was not fully understood and that the actual scale of the program was also underestimated due to the short recall period and the relevance of these transfers.
} 
Figure 6: Coverage of social insurance and social assistance (percentages)

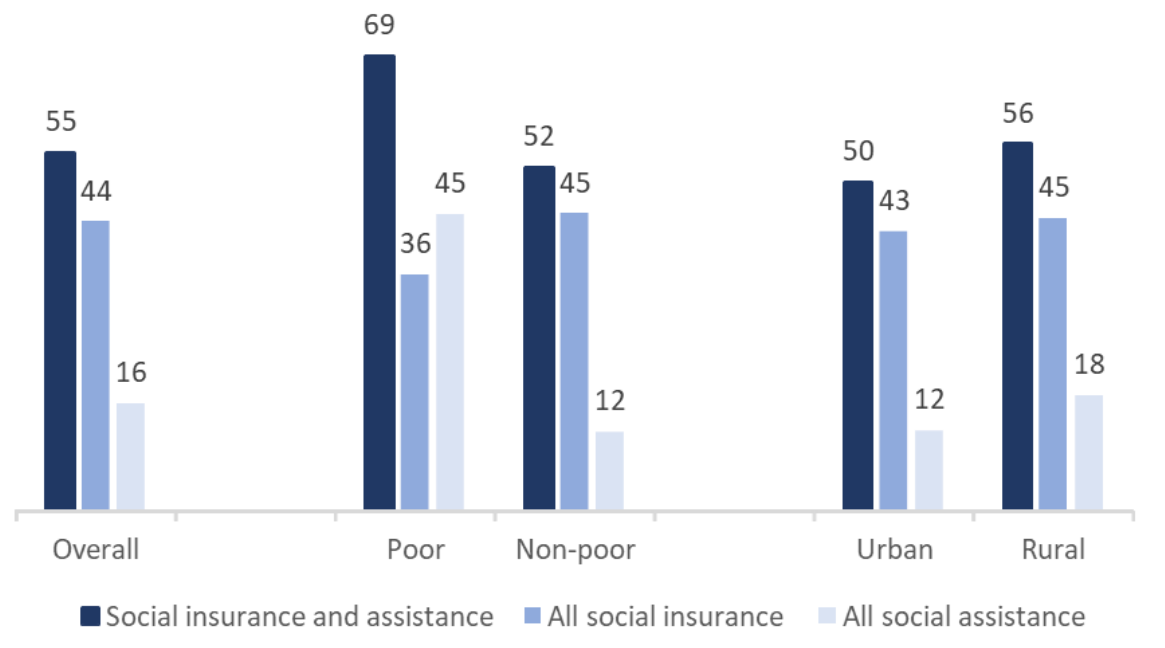

Source: Analysis of the L2CU 2018.

Note: Poor are defined using the international poverty line of US\$3.2 PPP. Social insurance includes old-age pension, disability pension, survivors' pension, sickness benefit, and childbirth/maternity leave. Social assistance includes family allowances (the three types), old-age allowance, disability allowance (for adults and children) and other allowances (loss of breadwinner), in-kind support, and monetary compensations for communal expenses for vulnerable groups.

Figure 7: Coverage of different social protection programs (percentages)

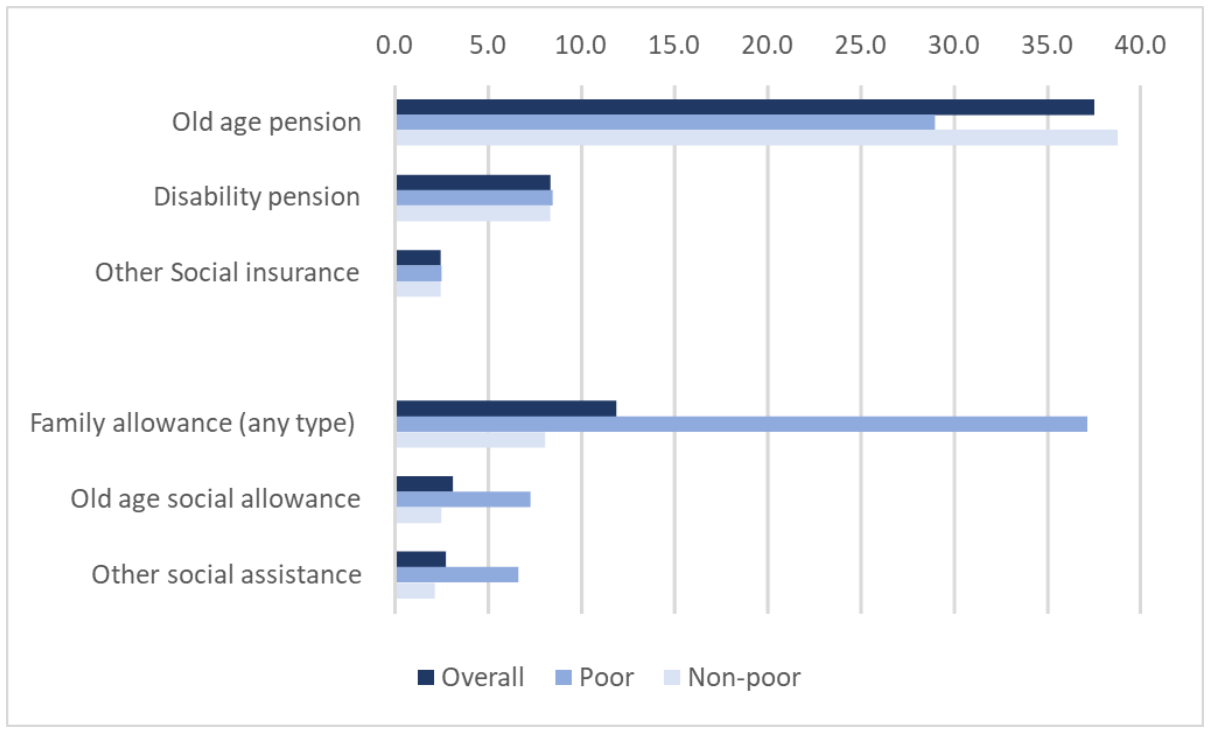

Source: Analysis of the L2CU 2018.

Note: Poor are defined using the international poverty line of US\$3.2 PPP.

It should be clear that whenever the poor are not covered, an exclusion error arises, whereas if the nonpoor are covered then an inclusion error exists. For example, the 37 percent coverage of the poor of low-income family allowances means that 63 percent of poor people are excluded. To consider the errors of inclusion it is necessary to look at the distribution of beneficiaries by poverty status or in terms of distribution of beneficiaries across quintiles. These are reported in Figure 8 for the three different types of low-income family allowances. Overall, all three allowances display a relatively good targeting, though children allowances have a higher leakage to the nonpoor than the other two allowances. Nevertheless, the large majority of all three allowances are received by the bottom 40 
percent of the distribution. Moreover, evidence suggests that some of the beneficiaries in the top quintiles are experiencing very high levels of health expenditure, which does not necessarily mean that they are better off.

Figure 8: Distribution of beneficiaries of different social protection programs by quintile and poverty status

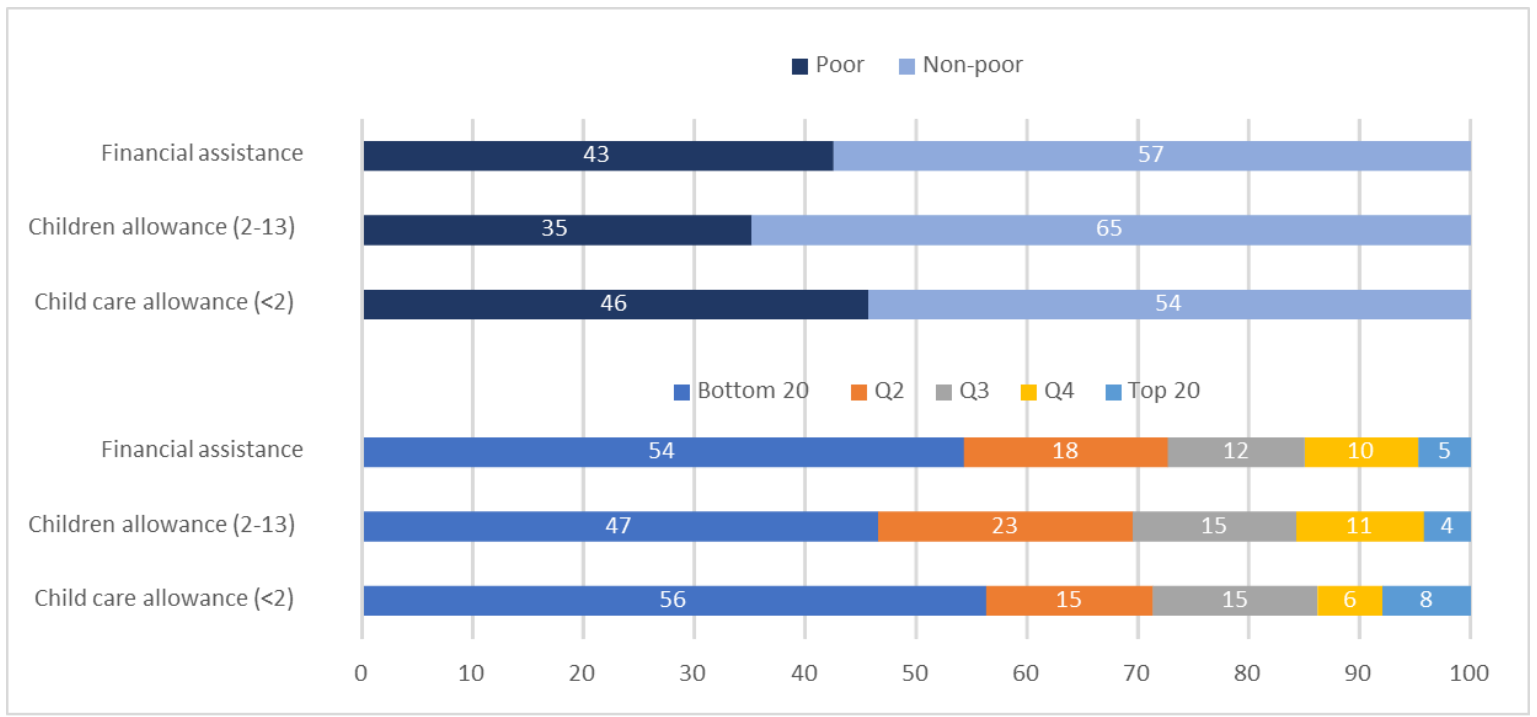

Source: Analysis of the L2CU 2018.

Note: Poor are defined using the international poverty line of US\$3.2 PPP.

\subsection{Amount of transfer and poverty impact}

Another important dimension of targeting is the amount of the transfer. Indeed, the ability of social assistance programs to reach the poor is not enough - the amount of transfer or the package of support provided to beneficiaries must actually protect people from poverty and enable them to reach adequate living standards.

The previous section showed how amounts of transfer differ across types of social assistance programs. The subsequent question is whether such amounts are sufficient to help reduce poverty.

Figure 9 shows the transfer/amount of the different low-income family allowances and for the overall social assistance as a percentage of consumption expenditure of beneficiaries for different programs, calculated across all beneficiaries of a certain program as well as among poor beneficiaries. Overall, in relative terms, the level of support among the poor is quite high on average, but while it is high for the child care allowance, it is significantly lower for children allowances. This result is largely expected given that the amount of transfer for children allowances is significantly lower than that of the other two allowances. However, this also shows that the lower amount for children allowances is likely to affect the ability of these households to move out of poverty. 
Figure 9: Transfer as a percentage of consumption expenditure of beneficiaries

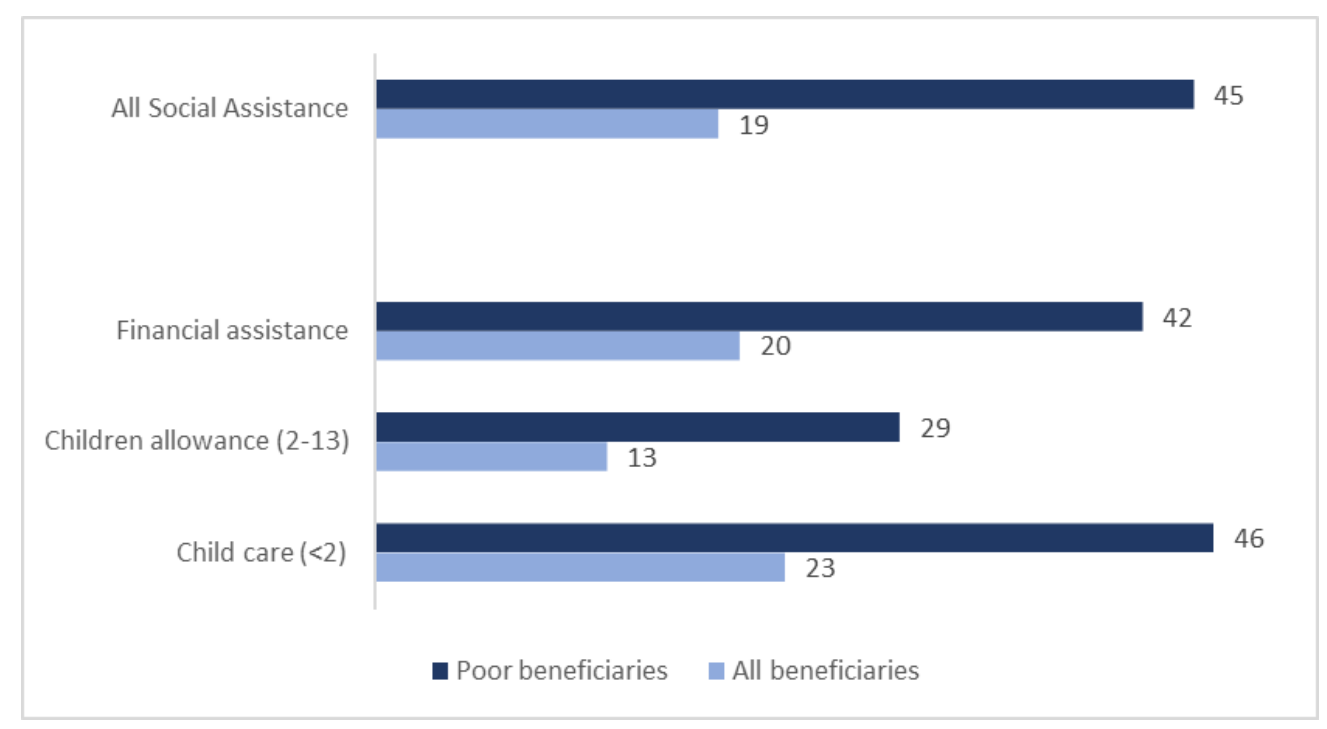

Source: Analysis of the L2CU 2018.

Note: Poor are defined using the international poverty line of US\$3.2 PPP.

Finally, Figure 10 summarizes the overall impact of family allowances on poverty. This figure: 1) simulates the poverty level in the absence of the low-income family allowances, ${ }^{5}$ which is 12.1 percent, rather than 9.6 percent; 2 ) determines the overlap between poverty and beneficiaries of low-income family allowances; and 3) shows the final poverty outcome after the transfer. All percentages shown are in terms of the overall population.

Figure 10 clearly highlights the three targeting problems:

1) Exclusion error: 7.4 percent of the population is poor and does not receive lowincome family allowances;

2) Inclusion error: 7.6 percent of the population receives family allowances, but is not poor;

3) Suboptimal amount of transfer: not all the poor who receive low-income allowances are moved out of poverty.

Therefore, scope remains to improve targeting in these three areas. The next section identifies reasons and possible solutions for the above errors.

\footnotetext{
${ }^{5}$ This is done by subtracting from the consumption aggregate an amount equal to the received transfer and recalculating whether people fall below the poverty line.
} 
Figure 10: Effect of low-income family allowances on poverty and relevant errors

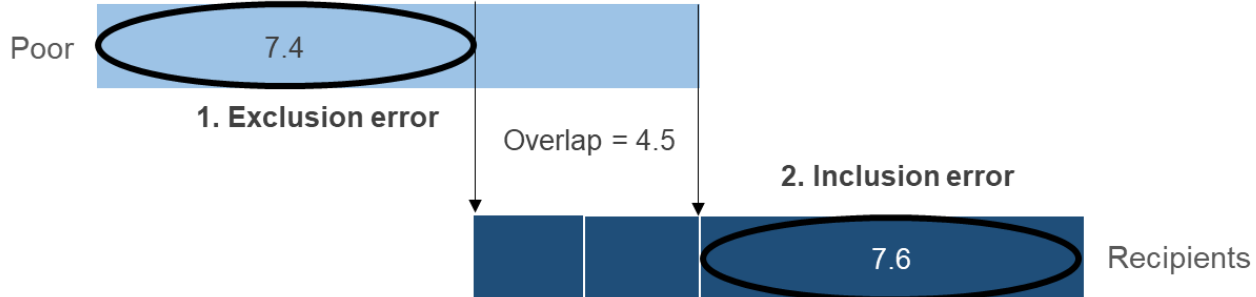

2.3 = beneficiaries out of poverty

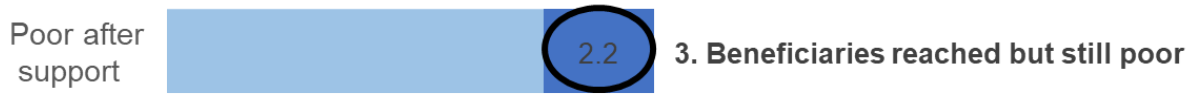

Source: Analysis of the L2CU 2018.

Note: Poor are defined using the international poverty line of US\$3.2 PPP. All percentages are computed with the population as denominator. 


\section{$4 \quad$ Implementation of targeting procedures}

The qualitative study offers insights into the implementation process of the targeting mechanism. While the study cannot claim to be country representative, it nevertheless covered different areas of the country and aimed at understanding whether the same rules were followed across different regions and what challenges were faced during implementation.

This section first looks at the administrative processes for low-income family allowances, which were once again given specific attention. It then discusses other allowances as well as employment services, particularly public works.

\subsection{Administrative processes for low-income family allowances}

In considering the administrative process, the analysis looks specifically at the "targeting steps," which consist of the following: outreach activities and informing people about the allowances; application and submission of documents; assessment of income based on submitted documents; assessment of living conditions of the household through household visit; and final decision of the commission with appeal procedures and reapplication process. In describing the process, the different perspectives of the population/applicants and the administration (mahalla and ESC) are examined. The focus is on explaining whether and how practice diverges from CR \#44 and on eventual implementation challenges.

From the outset it should be clarified that all processes to determine eligibility and assign the household entitlement to these allowances are paper-based. Only for monitoring purposes are applications and relative documents/information on beneficiaries entered in electronic format at the ESC.

\section{Outreach activities and information about allowances}

The first step in the process of targeting involves reaching out to people to inform them about the existence of the program, and in some cases, to encourage them to apply. Indeed, this is a very delicate, but often unregulated, step. Unfortunately, CR \#44 does not provide guidance on this aspect, and the qualitative study found very different approaches to informing and contacting people about allowances.

In most rural contexts mahallas say that they regularly monitor households' living conditions and keep a list of vulnerable households that is updated on an annual basis. In some mahallas, it was also reported that information is captured by street heads and patronage nurses who regularly visit households, who report to the mahalla representatives any difficult situations faced by households. Moreover, information is often provided through banners promoting information about allowances, or through monthly meetings where mahalla representatives explain about the different benefits.

Such activities are much more difficult in urban and peri-urban settings, however, and in some cases the mahalla representatives stated that everyone knows about such benefits and there is no need to further inform people. The qualitative study also found a case where the mahalla committee was not fully functional, as the mahalla was very recently established, and apparently no activities were carried out for a long time.

On the other hand, people reported that the best source of information is often neighbors, from where they hear about allowances and then go to the mahalla to verify whether they can apply. Nevertheless, people tended to confirm that in rural areas mahallas are the 
primary source of information and that they can usually approach the committee without problems. However, in urban settings the mahalla committee is not considered a reliable source of information, especially in Tashkent. In fact, people say that the mahalla cannot be trusted and that the same people can be treated very differently depending on the mood of the mahalla officer; they assert that the way in which the mahalla is able to provide a service depends very much on personal qualities of the committee members.

In general, very few people reported that they received information about benefits through mass media (TV, newspapers, or radio), and they recommend that regular meetings be held where the mahalla committee can provide information and respond to questions.

The quotes reported below give a sense of the different attitudes found in the mahallas and the very different experiences of people.

"Nowadays everybody knows about the opportunity to receive social assistance: we try to inform people and they consequently inform each other."

"We issue announcements, in addition we organize meetings in the café, during the weddings we explain to people. Many people come themselves and ask. We write them the list of the required documents."

"We inform citizens through the aksakals (heads of streets). They also act as advisors. Also they invite people for meetings held $2-3$ times per quarter."

"We made posters on required documents and allowances. They are available in the hall of the building of mahalla committee. When people come to apply for allowances, we explain everything."

"When we come to the mahalla for any help, we are always interested in what kind of allowance or help we can get there. And the chairman of the mahalla or the secretary of the mahalla, or one of the employees, always inform us in details about types of social benefit we are entitled to receive. They explain everything to us in detail."

"Mahalla provides no information. They do not know themselves much and do not provide information. Or they know and provide information only to "their" people. Others get information from friends, TV, hospital, from those who were in similar situation."

Source: Key informant interviews and focus group discussions, Qualitative Study 2018.

Notwithstanding the above different practices, it should be recognized that in all FGDs people were able to report all the main benefits. Instances of misinformation and cases where eligibility details were misunderstood did emerge, however.

Therefore, while it is fair to say that people know about the different type of allowances, the challenge comes in communicating eligibility rules.

\section{Application and submission of documents}

Once people decide to apply, the process is reported to be relatively straightforward. In general there are no difficulties with the submission of documents, since what is required are just photocopies of the original documents. Documents and application should be submitted before the $15^{\text {th }}$ of every month (though in some places it was reported to be the $5^{\text {th }}$ ) to qualify to receive an eventual transfer in the following month. By the $25^{\text {th }}$ of the same 
month the household assessment is made (income calculation and household visit) and the applicant is called to be present at the deliberation of the Commission, which should be gathered before the end of the month, so that the pay list for the coming month can be prepared by the $5^{\text {th }}$ of the following month.

However, it should be noted that some discrepancies arose in the adopted procedures of documents to be submitted for the application. In particular, in some mahallas it was reported that there is need to present a cadastral certificate stating the amount of land owned by household members. This is reportedly an expensive document that is not easy to obtain. However, in other mahallas, the committee trusts the information provided by the applicant and eventually information is checked at a later stage as part of the household visit. Another reported problem associated with the cadastral certificate is that it does not provide information on the quality or soil fertility of the land, and what is reported on the cadastral certificate could even consist of land unsuitable for farming. In turn, this could result in an unfair assessment of people's income.

Another document that is problematic is the income certificate, which is not issued when people work in informal settings. Finally, some regions and mahallas, as part of the application documents, request applicants to submit a photograph of the main door of their dwelling.

Nowhere after submission of an application do people receive a receipt as proof that they have lodged such application. This in most cases does not represent a problem, but international experience shows that this is an important step to ensure accountability of the staff processing the claim. In Uzbekistan this phase of the application process could result in undocumented delays in processing applications; indeed, during the FGDs it was reported that people were asked to wait before lodging an application or that payments were delayed and postponed. Issuing proof of application with a date of receipt ensures that the application is traceable and processing times can be monitored accurately, and even challenged by the applicant.

Finally, especially in urban settings it was reported that people who live in places other than their registered residence are not allowed to apply. However, this is more a problem related to the restrictions in place for official registration of internal migration, rather than with the principle of requiring residence in the place of application.

\section{Assessment of income based on submitted documents}

This step involves the calculation of incomes based on the submitted material and declarations and should be conducted within three days from receipt of the application.

Whenever a working-age, able-bodied household member does not report any income and the relative certificate as proof of such income, the procedure established by CR \#44 requires assuming an income equal to 2.5 times the minimum wage.

Exceptions to the above rule are cases where mothers take care of a child under two years, students, retired household members, and people engaged in dekhan farming (farming carried out by household members on a plot owned by the household). Dekhan farms consist of a plot at the periphery of the village, which on average is 0.20 hectares and no more than 0.35 hectares, but people also own tomorka, which is a plot of land near the house (Lerman 2008).

When households own their household plots, based on CR \#44 there is an imputation of agricultural income equal to 20 percent of the minimum wage for every 100 square meters of land owned. However, who can be considered employed in the dekhan farm and in the tomorka is sometimes a subject of controversy, and more guidelines would be useful. For 
example, is there a limit on the number of people who can be considered employed in a set amount of land?

In some cases it is possible that if the household owns only a tomorka, then people cannot be considered employed and so an imputation of 2.5 times the minimum wage is calculated even if the tomorka is of sizable proportions (such as 1,500 square meters). In such cases, a double imputation of income could occur.

"There is Decree No. 44. According to it the commission studies the financial condition, payment and so on, it would be good to include almost everything in it. In addition, very important is tomorka. It is in settlements, in rural areas. And in the cities there is no tomorka. Some people have 15 hundred sq. meters of land, some - 2 hundred square meters. In this view, whether according to the Decree No. 44 it is possible to include one person as occupied in tomorka, or he/she should considered as the unemployed is unclear. It would be good to resolve this issue. As currently, Decree No. 44 does not specify that. Tomorka is considered income-bringing asset and the person working at it is not considered employed. It is not clearly specified in the paragraph on income assessment. If it is clarified, then assignment of allowances would be easier. It would be good if it is clearly specified."

Source: Key informant interview, Qualitative Study 2018.

On the other hand, the agricultural imputation of income does not currently take into account whether households own livestock, even though this is an increasingly important source of income for the household and dekhan farming (Lerman 2008).

It was also emphasized that in some cases the imputation of income results in overestimating what people earn from temporary jobs; this in turn could result in excluding some poor households.

Only if after the above step the household is found to have an income below the eligibility threshold will the next step take place, otherwise a decision on eligibility is simply taken based on the application documents.

\section{Verification of household living conditions through a household visit}

This was the most contested step in the targeting process, reported as problematic by both by applicants and mahalla committees. It involves a household visit to verify household composition, determine living conditions, and verify whether what is stated in the documents matches the situation of the family. This step must be completed by the $25^{\text {th }}$ of the month and the visit is conducted by a group of five people. Key informants reported a lack of adequate guidance on this step, but somehow unwritten rules are determined locally to define the approach. Everywhere, car ownership results in exclusion of the applicant household, even in the contradictory case of a broken vehicle or inappropriate registration (see cases reported in the box below). In other cases approaches do vary, for example concerning the importance of home appliances. In some locations, specific importance is attached to the type of entrance of the main dwelling as a proxy to determine household living standards. In others, the committee takes the liberty to check "in people's fridges" or ask neighbors to confirm whether a certain household is really in need of assistance. There is a recognition that crude filters might be inappropriate and that while the flexibility in determining what to consider as proxies of poverty has its advantages, it also involves the possibility of adopting relative definitions of poverty. Other KIls raised the problem of families who did acquire some home appliances, but then were affected by some difficulties, and were of the opinion that having such assets did not undermine their need for support. 
"The husband registered a broken truck on his name, though they face difficulties with food, but actually the vehicle was on his name. How we should act in such cases? we paid them allowance, but now we do not know what to do. The truck does not work, but is simply standing in their house. If there is an inspection, we will definitely be asked why we pay them allowance when they have a car at home."

"One resident lived very poorly, it was in 2013-2014. As a result of visit to the household, it was revealed that a new car was purchased on his name. When notary documents were requested, we found out that actually the car belongs to his brother, who worked in Russia and purchased this car on his name. Then we stopped immediately paying him allowance and said that only once his brother comes and registers the car on his own name, we will continue paying him the assigned allowance."

Source: Key informant interview, Qualitative Study 2018.

Another problematic issue concerns the definition of household when multiple families live at the same address. In some cases all people residing at the same address are considered to be part of the household, but in others households are split. For example, if two brothers and their respective families live together with their parents, the younger married brother and his family are linked with the parents and considered one household, whereas the family of the older brother is considered on its own.

The problem stems from the lack of sufficient details in CR \#44, whereby two contradictory provisions are given. The first states that siblings of applicants who have their own family should not be included in the household composition; the second states that when more than one family lives at the same address, everyone should be included in the household for the purpose of assessing eligibility for low-income family allowances, provided that nuclear families with children do not apply separately for the same allowance.

In practice, it was observed that once again mahallas developed specific rules to determine whether families living at the same address are "running a joint household." Rules mentioned considered whether the household had a common boiler or the same kazan (traditional cooking pot); in other cases the focus was on whether families had a common address and the number of applications made.

\section{Final decision of the commission and appeal procedures}

After the document assessments and the home visit, the committee has the information that allows it to determine whether to grant the allowance to the applicant. This is done formally between the $25^{\text {th }}$ and the end of each month in an assembly to which the applicant is invited to attend in person. In some mahallas, if the applicant is not available, the decision is postponed to the next month when the applicant can be present. However, in other mahallas other household members are invited instead (this approach is indeed possible based on CR \#44). In case of refusal the assembly should explain to applicants the reasons and the decision is recorded in appropriate minutes.

If people disagree with the decision they can theoretically appeal, but this hardly ever happens. During one FGD, people explained that ultimately they need to keep a good relationship with the mahalla.

Overall, both the KIIs and the FGDs confirm that the process usually maintains the timeline described in the regulations. 
While official refusals of cases pronounced in the assembly follow the regulations, usually problems occur at an early stage in the acceptance of the application. Indeed, a problem reported in several KIls was that of unavailability of funds and of caps in the number of "allowed" recipients by mahalla. To address this issue, people are asked to postpone their application or in some cases households are granted an allowance for a lower amount and of a lower duration. For example, rather than providing the child care allowance (children aged <2), the children allowance (children aged 2-13) is granted. This was confirmed by some FGD participants and evidence of this also arose in the L2CU survey, where 10 percent of all beneficiaries of children allowances have a child less than two years old.

When eligible families cannot receive the allowance, the mahalla tries to support them through donations of wealthy households and support that is provided and organized locally. However, this ultimately depends on the wealth and prosperity of each mahalla.

\section{Reapplication process}

According to CR \#44 the duration of support of these allowances is 6 months for children allowances (children aged 2-13) and for financial assistance, and 12 months for the child care allowance (children aged $<2$ ). Within the above entitlement duration, allowances are stopped or recalculated whenever clear eligibility criteria change: for example, a child turns 2 , or 14. However, while some mahallas claim that they monitor such conditions on a regular basis, including changes in the income sources of the beneficiaries, others said that this does not usually happen.

The same resolution also considers the possibility of reapplication. For the child care allowance, reapplication can start from the month before the end of the entitlement, thus ensuring no interruption. However, for the other two allowances, people are allowed to reapply only after the entitlement expires. By design this introduces at least one month of interruption in support. Reapplication follows exactly the same process of a new application.

Once again, reapplication is an area of significant differences across locations. In Tashkent people need to wait six months before being able to reapply. In other places people are asked to wait three or four months, or allowances are considered to be a one-off assistance to give everyone the possibility to receive some support. This is likely to be a way for mahallas to manage "capped resources" for the allowances. Some people reported during FGDs that they do not reapply for allowances because they do not want to "spoil" the relationship with the mahalla committee.

The FGDs revealed cases of poor households that do not apply for support as they feel ashamed to ask for help, and that the treatment received in mahallas discourages people from applying. Overall, the main problems preventing people from receiving allowances, however, are the capped funds at the mahalla level and the assigned maximum number of beneficiaries per month.

People also reported cases of abuse/corruption, whereby relatively better-off households received such allowances, but these cases were not considered widespread.

Finally, it is useful to point out the different perspectives of the population and administrators concerning exclusion and inclusion errors. Indeed, the prevailing opinion among the population is that it is worse when poor people are excluded from allowances, whereas administrators consider it worse to provide allowances to nonpoor people. Moreover, the opinion often expressed by administrators is that allowances should only be seen as a very temporary support. Sometimes this approach is likely to influence the way allowances are granted beyond the written eligibility criteria. 


\subsection{Administrative processes for other allowances managed by the Pension Fund}

The outreach and information activities discussed for the low-income allowances are also relevant for other social allowances. Even if the administration of these allowances is managed by the district PF, mahallas still play a fundamental intermediary role. Indeed, mahallas together with patronage nurses maintain an overview of PWD in the location, are aware of children with disabilities, and support applications for disability pensions. Moreover, mahallas provide the list of school-age children of low-income households who should receive winter clothes from schools.

Nevertheless, applications for old-age allowances, disability allowances (since childhood and acquired), survivors' allowances, and compensation payments for utilities must be submitted to district-level offices. Documents to be submitted are generally straightforward as they include a photocopy of a passport or birth certificate, a residence certificate, and a photograph of the applicant. The tax personal identification number can be retrieved with the above information, and is necessary to process the application and verify people's eligibility. However, the disability certificate, and in particular the need for a continuous renewal of disability status and its associated costs, was consistently reported in the FGDs as being excessive and very tough for PWD. The disability certificate is granted by the Labor and Medical Expert Commission (VTEK) and its validity can vary between six months and five years depending on the specific condition. It not only requires PWD to renew their status at the end of their certificate's validity, but also to undertake specific medical checkups in-between to be able to confirm their disability status. People questioned whether all these exams are really required as they are often conducted in cases of permanent conditions and ultimately represent a significant economic and emotional burden.

"Collecting documents is very tiresome. It is requested to collect certificates from different places. That is a lot for people. Now we go to hospital for treatment three times a year. Then we collect other documents, and we provide them to VTEK. And we have to bring the child for examination. All this is very tiresome. Doctors know all types of diseases. And depending on the diagnosis it is possible to extend the period of receiving disability allowance. Doctors could extend the period of allocation of allowance depending on the diagnosis. In general, this term should be extended in order that families with disabled person do not suffer more."

"The most difficult in the process of application for disability allowance is request to provide abstract from hospital every 120 days, in other words, my husband should pass treatment every 3 months within the year."

Source: Focus group discussion, Qualitative Study 2018.

For allowances provided by the PF, it is significant to note that a mechanism of appeal is necessary. This sometime occurs through the President's Office for Complaints, as demonstrated by the example reported below.

"A woman, whose husband was mentally ill, applied for disability benefit and was refused. She disagreed with the decision and reasoning and complained to virtual reception of the President. After applying to the President, the decision was reconsidered in the favor of the household."

Source: Focus group discussion, Qualitative Study 2018.

Interviews with PF offices revealed the problem that many people face in documenting their contributive history. The problem stems from lack of adequate recording of contributions from enterprises that no longer exist. Especially in the 1990s many organizations opened and closed without submitting relevant documentation of their employee and contributions. 
The inability to properly document a person's contributive history results in assigning a lower pension, and in many cases, just the minimum pension.

\subsection{Public works and employment services}

The ESC provides a number of labor market services, some of which are also offered through the intermediation of mahallas, in particular public works and the provision of microloans at preferential rates. The ESC also organizes job fairs to make people aware of different job opportunities.

Public works and microloans were indeed the programs most mentioned during the FGDs. Some people reported being given temporary job positions, and that although the salary was low and the period of employment limited, it was nevertheless helpful.

However, in many rural areas it was also recognized that most public work job opportunities are seasonal, when people are anyway more likely to find job opportunities, and that wages are very low. This problem was also recognized by many key informants, who said that offering employment in rural areas in the winter season is complicated and that if jobs are offered in urban areas, transportation costs can preclude people from accepting the job placement.

People are also of the opinion that the ESC can only provide jobs for those with some higher-level qualification, and that few opportunities exist for people with secondary education.

There were also reports that winter job positions in a factory were promised if people would first work picking cotton, but at the end of the cotton-picking season the factory job was not provided.

FGD participants viewed microloans as not a solution for everyone, since they require some entrepreneurial skill. Moreover, in some cases microloans were not in monetary form; instead, people were given livestock or other goods. Some people reported that substandard products, such as nonpedigreed livestock, were received.

Finally key informants made some important observations related to their available resources and staff capacity. While interviews with the PF revealed no problems with resources and staff, the situation was radically different in the ESC, where in many places it was reported that the number of inspectors is insufficient, people are overworked, and their pay is relatively low. It was proposed that at least one experienced staff with relevant background knowledge to deal with financial issues should be hired in each mahalla. 


\section{Policy recommendations}

The recommendations herein focus primarily on the low-income family allowances, with some general comments on other allowances and employment services, including public works.

\subsection{Low-income family allowances}

The targeting study provided robust evidence that relative targeting of social assistance is quite good, in the sense that a disproportionate size of the budget for social assistance is received by the bottom quintile and the poor. However, very significant exclusion errors occur, and based on the analysis of the L2CU survey and the current eligibility threshold for low-income family allowances, it is clear that many more households should be eligible for support. Moreover, while some of the allowances provide relatively generous support, in other cases the amount of the transfer appears insufficient and scope remains for some optimization.

While in 2018 the Government of Uzbekistan increased the budget allocated for social assistance, a number of significant design and implementation problems are still affecting the targeting of social assistance transfers, in particular the allowances for low-income families.

\section{Outreach activities}

Currently, no guidelines exist on this fundamental aspect of the targeting process, resulting in mahallas taking very difficult approaches. It would be useful to produce guidelines that standardize such processes and in particular promote regular meetings where mahallas give more in-depth information on eligibility criteria and "question and answer" (Q\&A) sessions. The experience of other countries shows that production of a Q\&A booklet for the administration and frontline staff is very useful.

\section{Budgeting process}

The qualitative study highlighted that one of the most significant reasons for exclusion of beneficiaries is the way budgeting works in practice, since many mahallas report that they have a monthly cap on the number of beneficiaries and the budget. The cap 1) results in rationing behavior, whereby limited resources are spread across eligible households, assigning allowances at a lower amount, or 2) triggers a rotating approach, such that applications are de facto postponed or payments of eligible applicants are delayed.

The MoF significantly increased budget allocations for low-income allowances, but the problem at local level might be due to old expenditure patterns and behaviors. It is necessary to investigate and clarify the practical obstacles in establishing more flexibility in the use of budget to respond to actual demand.

Ensuring budget flexibility and a responsive system is extremely important if social assistance intends to respond to difficulties created by the government's macroeconomic reforms. Budget should not simply be based on previous expenditure patterns, but more could be done to actually estimate the needs of each community. In this regard a social registry could help produce a more complete picture of such needs, in turn forming the basis for better budget allocations. 


\section{Income calculation}

The current calculation of income and eligibility rests on two fundamental steps:

- the definition of a "household" and consequent identification of household members; and

- the rules to impute household income.

It is necessary to provide more detailed guidelines on who should be considered a household member, especially in circumstances where more than one family lives at the same address and if the household has members working abroad.

Concerning income imputation procedures for every able-bodied, working-age person, it is important to be aware that this could be responsible for significant design exclusion errors. The other important element of income simulation relates to the way agricultural income is indirectly imputed. It is possible that this calculation underestimates income when households own livestock.

The imputation of an income amount of 2.5 times the minimum wage assumes that people always have access to informal income sources, but it is also an administratively convenient practice that does not encourage people to register with the ESC.

The current draft resolution of the Cabinet of Ministers with amendments to CR \#44 to be piloted in Syrdarya region no longer stipulates such imputation, but rules that the presence of a family member capable of working but not reporting official income sources makes the household ineligible for support.

Experience of other countries shows that it is preferable to be inclusive at this stage of the application process and to instead control potential inclusion errors at the next step.

The recommendation is to conduct more analysis of the L2CU survey or the Household Budget Survey to simulate the administrative calculation of household income eligibility and verify the extent to which the income imputation procedures are responsible for administrative exclusion or inclusion errors and how eventual problems could be corrected.

Another recommendation is to ensure that people not working are always registered with the ESC, so that when possible, adequate support is provided to these people to enter the labor market (see below regarding public works).

\section{Indirect living conditions assessment}

Currently, no standard approach exists to determine whether a household should be considered poor or not based on its living conditions. Mahallas clearly seem to be adopting location-specific rules, which ultimately results in a relative definition of poverty, and in turn risks excluding poor households in poor locations or including nonpoor households in relatively better-off locations.

The recommendation is to verify the extent to which the above problem is occurring and to develop and test whether an alternative proxy model approach could theoretically provide better results. From an equity perspective it is important to ensure that everyone is treated fairly; development of a more robust proxy system could improve the current practice.

\section{Ensuring accountability and traceability of applications}

One final important recommendation concerns the need to ensure accountability in the application process to prevent applications from being disregarded or postponed or 
payments delayed. This can be done by ensuring that people have the right to apply, are aware of this, and receive a receipt of their application with date of application and a unique registration number. This is important also to ensure that timelines for processing applications are followed.

While timing is usually respected, the qualitative study identified not only many instances in which applications were postponed because of funding inflexibility, but also came across a case of a nonoperational mahalla, which resulted in a long-term absence of support for people living in that community.

The Government of Uzbekistan is already moving in the right direction concerning this specific aspect: draft amendments to CR \#44 to be piloted in Syrdarya region in connection with the creation of a "Unified Register of Social Protection" regulate the need for a "notification of acceptance," though this is expected to be communicated only via email or phone.

\section{Amount of transfers}

Evidence provided through analysis of the L2CU survey showed that the way the amount of transfer is currently decided is not always optimal. Households falling below the same income threshold receive very different levels of support. This approach is not justified by the different needs of households. More specifically, while some households receive a very generous amount (child care allowance for children under 2 years), the children allowance (children aged 2-13) is too low, so these transfer amounts need to be reviewed to better balance support according to household needs.

The recommendation is to conduct further specific analysis on the L2CU survey or the Household Budget Survey to determine whether alternative approaches considering household size and needs could provide better poverty outcomes.

\section{Reapplications}

Currently, with the exception of child care allowances (children $<2$ years) the system directly or indirectly discourages reapplications: at least a one-month gap is forced by design, and in practice, many people's reapplication is delayed for a longer period.

The recommendation is to review this approach to ensure 1) the possibility of continuous assistance whenever households remain eligible, and 2) that the process of re-applying is simplified.

\subsection{Other social assistance programs}

While the study could not look into the details of how disability is assessed and confirmed over time, many FGD participants were deeply unsatisfied with the way this is done, since it implies significant continued and unnecessary financial and emotional costs. Therefore, the recommendation is to review how this operates in practice and whether there are ways in which the process can be improved and simplified.

\subsection{Public works and employment services}

Although public works schemes started only recently, positive signs of their operations have already emerged, with people reporting that this is a way to support some households. However, a lot of work remains to better integrate social assistance and employment services. In some parts of the administration, public works are described and seen as a 
way to take people off the list of social assistance beneficiaries. Some FGD participants perceive that to now receive assistance, it is necessary to do some public work.

On the contrary, the goal should be to provide a service to people to enable their entry into the labor market and to ensure they have the required skills to do so.

The problem is partly related to the automatic income imputation whenever people are of working age and able to work but do not report any official income. In such cases, the solution is not to simply impute an income, but should involve a more proactive role of linking these people with employment services. However, for this to be done effectively, more investment in the ESC is needed, in terms of both number of personnel and their training. 


\section{References}

Al Mar Consulting. 2018. "Identifying the Demand for Social Protection in Uzbekistan, Targeting Assessment Report." Tashkent, Uzbekistan.

Government of Uzbekistan. Draft Resolution of Cabinet of Ministers. "Temporary Provisions on Procedures of Granting and Payment of Social Allowances and Financial Assistance to Needy Families in Syrdarya Region Through the 'Unified Social Protection Registry' Automated Information System." Tashkent, Uzbekistan.

2013. Resolution of Cabinet of Ministers No. 44, 15/02/2013. "Approval of Provision on Procedures of Assignment and Payment of Social Allowances and Financial Aid to Low Income Families." Tashkent, Uzbekistan.

Lerman, Z. 2008. "Agricultural Development in Uzbekistan: The Effect of Ongoing Reforms." Discussion Paper No. 7.08, The Hebrew University of Jerusalem. 


\section{Annex A Statistical table}

\section{Coverage of social assistance and social insurance transfers}

\begin{tabular}{|c|c|c|c|c|c|c|c|c|c|c|}
\hline & & \multicolumn{5}{|c|}{ Quintiles of per capita consumption, net of all SA } & \multicolumn{2}{|c|}{ Poverty Status } & \multicolumn{2}{|c|}{ Area of residence } \\
\hline & Total & Q1 & Q2 & Q3 & Q4 & Q5 & Poor & Non-poor & Urban & Rural \\
\hline \multicolumn{11}{|c|}{ Direct and indirect beneficiaries } \\
\hline All social protection & 54.6 & 67.0 & 52.9 & 53.3 & 51.5 & 48.4 & 69.2 & 52.4 & 50.1 & 55.9 \\
\hline All social insurance & 44.1 & 40.4 & 43.0 & 45.1 & 47.0 & 44.8 & 35.9 & 45.3 & 42.5 & 44.5 \\
\hline Old age pension & 37.5 & 33.3 & 34.9 & 39.1 & 41.3 & 39.0 & 29.0 & 38.8 & 37.2 & 37.6 \\
\hline Disability pension & 8.4 & 8.7 & 7.6 & 8.1 & 9.0 & 8.3 & 8.5 & 8.3 & 7.8 & 8.5 \\
\hline Other Social insurance & 2.5 & 3.1 & 3.2 & 2.0 & 1.9 & 2.2 & 2.5 & 2.5 & 1.4 & 2.8 \\
\hline All social assistance & 16.3 & 37.8 & 16.2 & 13.5 & 8.0 & 6.4 & 45.1 & 12.0 & 12.3 & 17.5 \\
\hline Family allowance (any type) & 11.9 & 30.9 & 11.1 & 8.7 & 5.2 & 3.5 & 37.2 & 8.1 & 8.5 & 12.9 \\
\hline Old age social pension & 3.1 & 5.4 & 4.1 & 2.9 & 1.7 & 1.5 & 7.3 & 2.5 & 1.9 & 3.5 \\
\hline Other social assistance & 2.7 & 5.6 & 2.5 & 2.3 & 1.6 & 1.8 & 6.6 & 2.2 & 3.0 & 2.7 \\
\hline
\end{tabular}

Notes:
Program coverage is the portion of population in each group that receives the transfer.

Specifically, coverage is: (Number of individuals in the group who live in a household where at least one member receives the transfer)/(Number of individuals in the group).

Program coverage is calculated setting as expansion factor the household expansion factor multiplied by the household size.

Source: Analysis of L2CU 2018. "SA" stands for Social Assistance. 